\title{
New technology in echocardiography II: imaging techniques
}

\author{
W Norman McDicken, Carmel M Moran, Peter R Hoskins, Mark J Monaghan, \\ George R Sutherland
}

Department of

Medical Physics and

Medical Engineering,

University of

Edinburgh, Edinburgh

W N McDicken

C M Moran

P R Hoskins

Department of

Medicine, University

of Edinburgh,

Edinburgh

G R Sutherland

Department of

Denmark Hill, London

M J Monaghan

Professor W N McDicken,

Physics and Medical

Edinburgh, Edinburgh

EH3 9YW, UK.
Cardiology, King's

College Hospital,

Correspondence to:

Department of Medical

Engineering, University of

\section{Intravascular techniques}

Intravascular ultrasound (IVUS) imaging of coronary arteries has become possible due to improvements in the miniaturisation of ultrasound transducers. Intravascular B scan imaging consists of cross sectional imaging of vessels by miniature ultrasound transducers mounted on wires which are contained within a catheter sheath (fig 1). The scanning beam is directed at right angles to the axis of the wire and sweeps through $360^{\circ}$ (fig 2 ). In addition to imaging of structures related to the vessel wall, efforts are being made to classify the tissues present with a view to predicting the success of interventional procedures. Few commercial companies produce such systems. Three
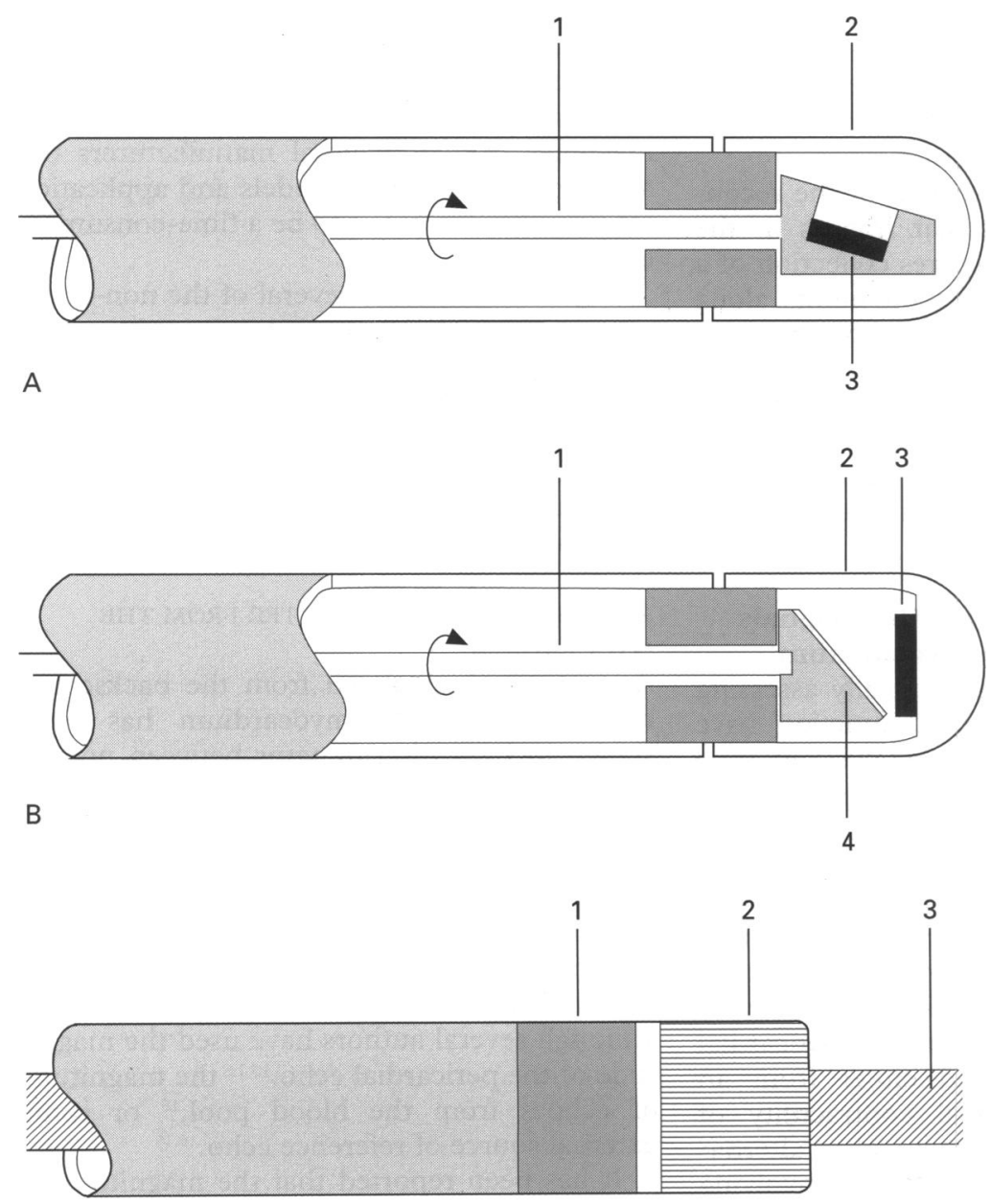

C

Figure 1 Catheter scanners. (A) Rotating transducer, drive shaft (1), window (2), Figure 1 Catheter scanners. (A) Rotating transducer, drive shaft (1), window (2),
transducer (3); (B) rotating mirror, drive shaft (1), window (2), transducer (3), mirror (4); (C) circular electronic array, preamplifiers (1), transducer elements (2), guide wire (3). (Reprinted by permission of Kluwer Academic Publishers from Bom N, ten Hoff H, Lancee CT, Gussenhoven WF, Bosch $\mathcal{F}$ G. Early and recent intraluminal ultrasound devices. Int J Cardiac Imaging 1989;4:79-88.) approaches to the generation of an ultrasound image have been reported. ${ }^{1}$

- A single transducer element is rotated directly by the drive shaft.

- A single element is fixed and the ultrasound beam swept through $360^{\circ}$ by reflection of the beam from a rotating acoustic mirror.

- Array of elements are arranged in a circle around the catheter tip.

In this last approach typically 32 elements are used in present systems and the beam is rotated in a circle by firing groups of elements in turn. This is technically demanding and it is difficult to generate a narrow beam with a relatively small number of elements. With mechanical scanners geometrical distortion of the image may occur as a result of changes in the angular rotational speed of the drive wire. One advantage of the array systems is that sweeping of the beam is electronically controlled and such distortion will not occur.

The ultrasound beam characteristics determine the spatial resolution of the intravascular image which in turn determines the ability to perceive detail in the image. Measurements of the spatial resolution characteristics of a single $30 \mathrm{MHz}$ element intravascular scanner have been reported, where it was noted that considerable deterioration of the lateral spatial resolution occurs with increasing depth. ${ }^{2}$ The limited space available in general makes it difficult to incorporate the advanced beam focusing techniques found in external transducers. Prototype single crystal catheter scanners have been described operating at frequencies as high as $60 \mathrm{MHz}$.

\section{Three dimensional imaging}

3D ultrasonic techniques for visualisation of the heart have been reported for 20 years. ${ }^{3}$ With the ever increasing speed and storage capacity of computers, 3D manipulation of ultrasonic images has in recent years become feasible on a commercial basis; this requires the transfer of a complete set of $2 \mathrm{D}$ images to the computer. Several approaches are possible for acquisition of the 2D ultrasound images. One common approach is to acquire a set of transoesophageal $2 \mathrm{D}$ ultrasound images using a multiplane probe. ${ }^{5}$ The transducer is mechanically rotated in steps through $180^{\circ}$, and sequential scans are acquired and stored by the computer. The multiplane probe has been used to acquire a set of B scan images of the left ventricle. ${ }^{6}$ Automatic algorithms may be employed to trace the edges of the left ven- 


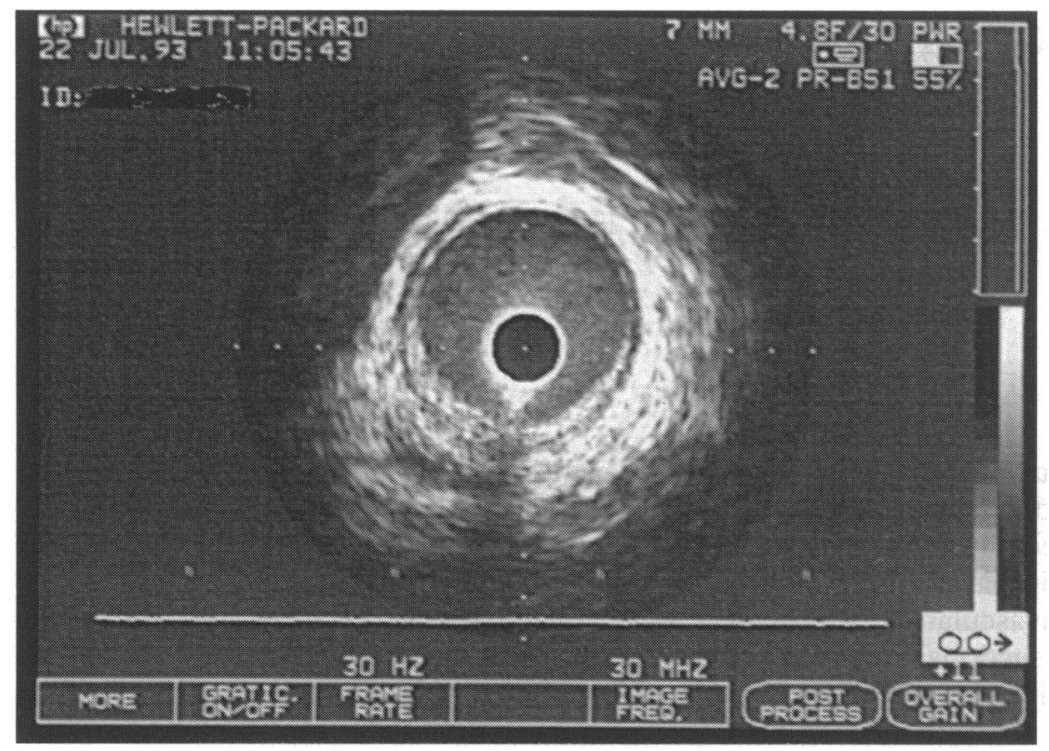

Figure 2 Pulse-echo $B$ mode image of diseased artery walls obtained with a rotating 30 $\mathrm{MHz}$ transducer. access to the ultrasound data earlier in the processing path before signal manipulation. Unfortunately in many instances gaining access to the ultrasound data early in the ultrasonic processing path is dependent on the goodwill of the ultrasound manufacturer. In addition, some of the larger ultrasonic manufacturers work with the analogue signal till late in the signal path, necessitating access to a high-speed digitiser and concomitant computer facilities to capture and store the data. Alternatively a method which bypasses all this off-line analysis has now been implemented on-line by one company (Hewlett Packard, USA) which permits a region-of-interest (ROI) to be interactively chosen and the real time variation of integrated backscatter (IB), a parameter calculated from the RF data, to be continuously displayed on the ultrasound screen.

Without access to the RF data, the image sequence can be digitised at the end of the signal-processing path using a frame-grabber connected to the scanner video output and the variation in grey-scale intensity over a ROI calculated using standard software image analysis packages. ${ }^{9-11}$ In some instances, for an individual machine application and set-up it may be possible to use test phantoms to measure and compensate results for the effect of some of the non-linear processes which occur within the ultrasound machine. Because differences in processing paths occur not only between machines from individual manufacturers but also between different models and application set-ups, this can prove to be a time-consuming exercise.

Figure 5 illustrates several of the non-linear processes which occur within an ultrasound machine and which result in the dynamic range of the echo signals being compressed from $100 \mathrm{~dB}$ to $20 \mathrm{~dB}$. These processes are time gain compression (TGC), logarithmic compression, demodulation, and scan conversion compression.

\section{ANALYSIS OF RF BACKSCATTER FROM THE} MYOCARDIUM

A parameter calculated from the backscatter reflected from the myocardium has been shown to be a discriminator between normal and infarcted myocardium. ${ }^{12}$ The parameter, integrated backscatter, is the ratio of the energy backscattered in the acoustical signal arising from the tissue volume of interest divided by that from a reference reflector. For cardiological application, no obvious choice of an anatomical reference reflector exists, although several authors have used the magnitude of the pericardial echo, ${ }^{13}{ }^{14}$ the magnitude of echoes from the blood pool, ${ }^{15}$ or some external source of reference echo. ${ }^{1617}$

It has been reported that the magnitude of integrated backscatter measured from normal canine myocardium varies in a predictable manner throughout the cardiac cycle (fig 6) ${ }^{18}$ with minimal values at end systole and maximal ones at end diastole. This cyclic variation has been confirmed clinically in the left ventricular posterior wall and the interventricular are optimised to enhance ventricular and valvar dynamics rather than changes in the lowlevel backscatter signals scattered from within the myocardium, this latter technique requires 

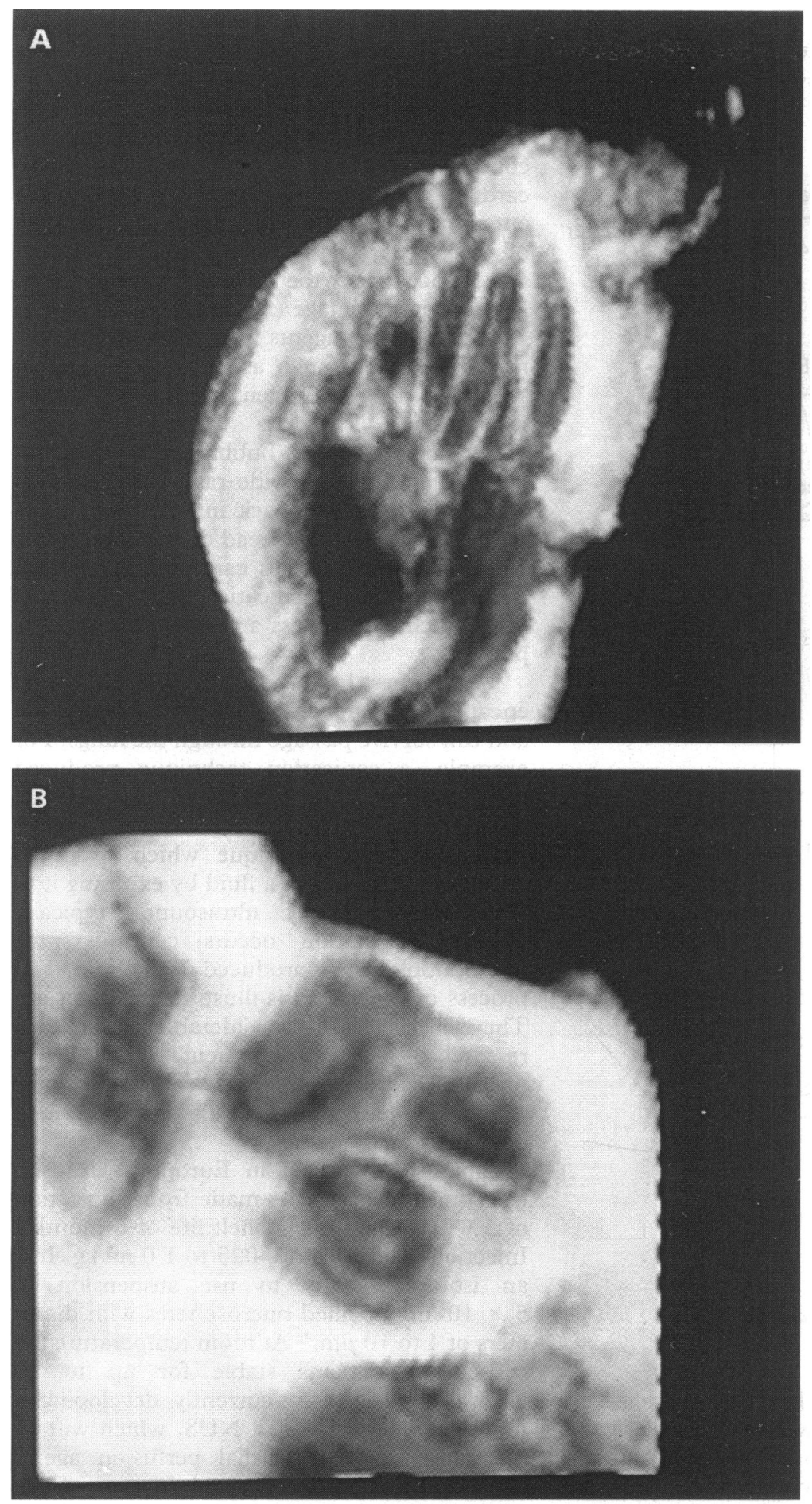

Figure 3 Photographs of displays of $3 D$ scans of the left ventricle and valve apparatus $(A)$ and triscupid valve $(B)$. The images can be rotated on the display to provide an appreciation of the third dimension. septum in patients with normal ventricular function when imaged from the standard precordial long or short axis scanning positions. In addition, an overall increase in the magnitude of integrated backscatter has been noted from ischaemic or infarcted myocardium ${ }^{19-22}$ with a concomitant reduction or complete absence of cyclic variation also associated with these regions. ${ }^{23}$ In addition upon reperfusion of myocardial regions which had suffered an ischaemic insult, the recovery of this end diastolic to end systolic variation seemed to be an earlier and more sensitive indicator of future

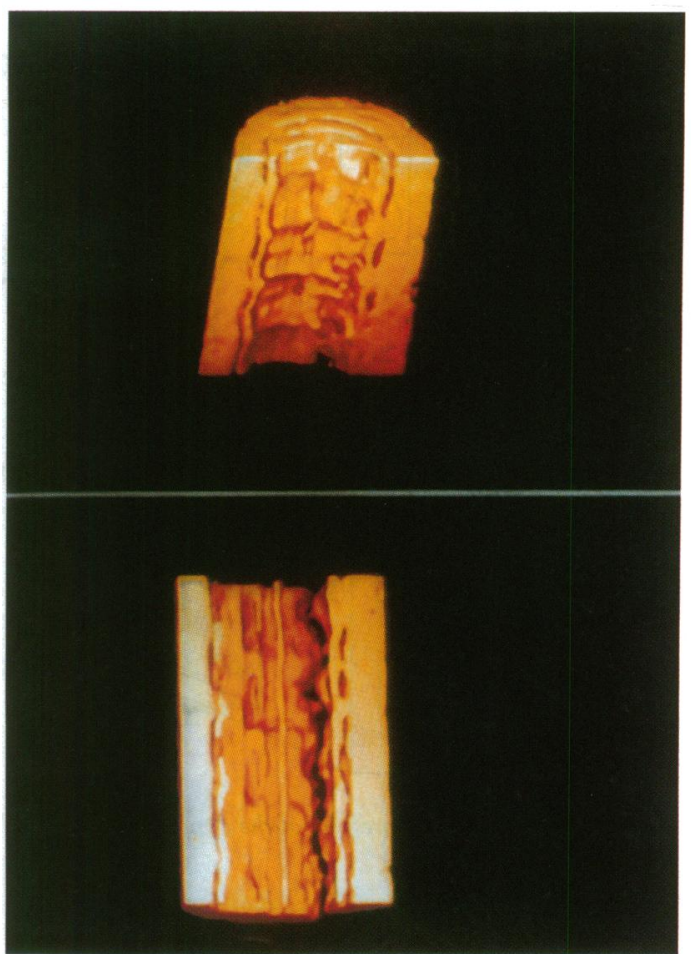

Figure 4 Photographs of a display of a $3 D$ scan of an artery. Rotation of the image provides an appreciation of the third dimension (Courtesy of $\mathcal{F}$ Gardener.)

tissue integrity than the dynamics of wall thickening. ${ }^{24-27}$ In dilated or hypertrophied cardiomyopathies an increase in the magnitude of integrated backscatter was also observed ${ }^{28-31}$ and a reduction in the normal cyclic variation of integrated backscatter. ${ }^{32}$

Despite the large amount of clinical data which is currently available, of which a few are cited above, integrated backscatter as an indicator of tissue viability is still largely not used as a routine clinical tool. Several factors contribute to this. Firstly, cyclic variation within the myocardium has almost exclusively been observed only from the precordial long and short axis views. ${ }^{33}$ In a recent study, however, cyclic variation from the myocardium was shown to be present when measured from the apical two and four chamber precordial views of the heart, although in these views the maximum in integrated backscatter is not always coincident with end diastole nor the minimum with end systole. ${ }^{34}$ Clinical trials are currently underway to establish whether this variation also changes with abnormal left ventricular function. If so, then it will be possible to measure changes of integrated backscatter from all myocardial regions of the left ventricle. Secondly, as stated previously, until recently access to the ultrasonic RF data has generally been restricted to a few research centres. With ultrasound companies giving wider access to this data, it will soon be possible to quantitate changes in myocardial signatures independently of the control settings of the ultrasound scanner.

\section{Myocardial contrast echocardiography} CONTRAST AGENTS

Contrast agents, in particular those that depend on the extremely high scattering prop- 


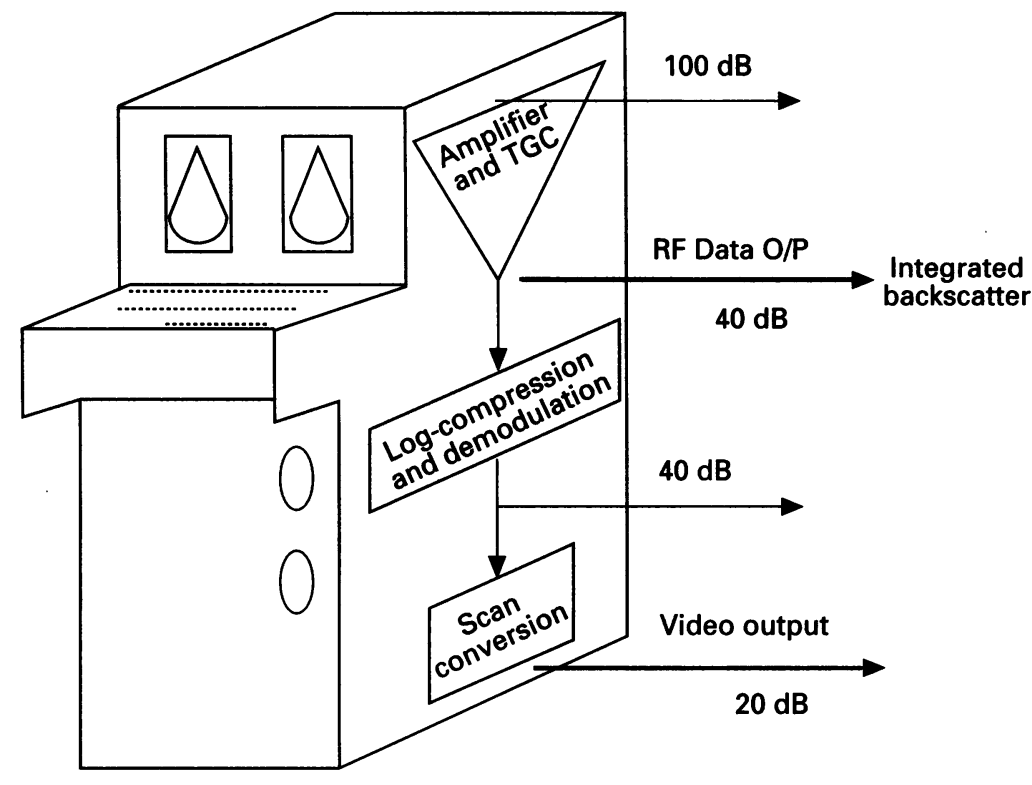

Figure 5 Stages of compression of the dynamic range of echo signals in a conventional ultrasonic scanner.

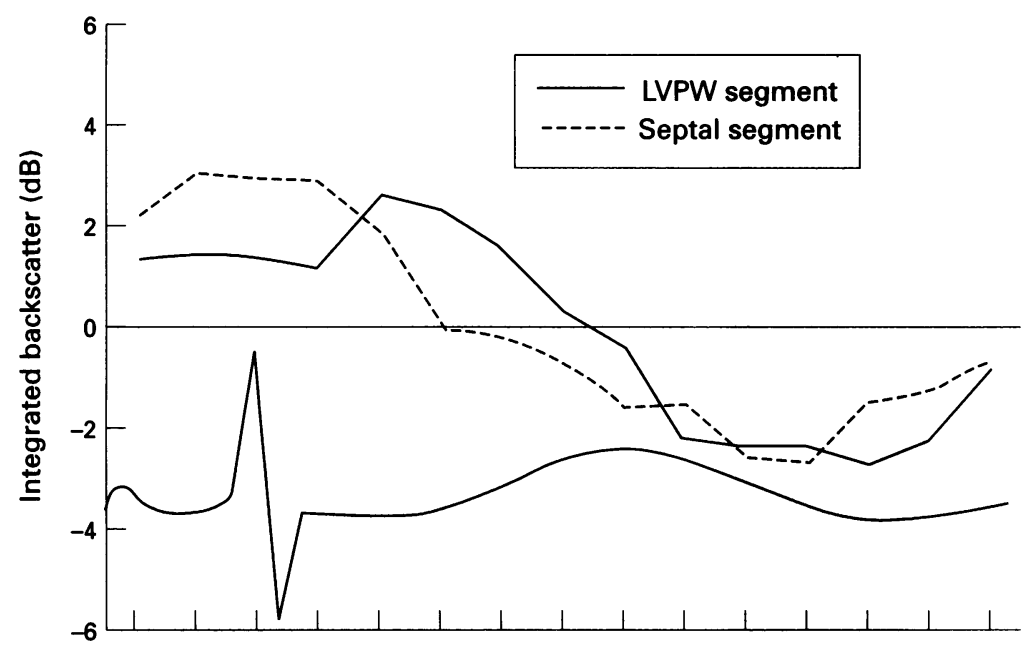

Time (1 cardiac cycle)

Figure 6 Variation of integrated backscatter echo signal over a cardiac cycle.

erties of microbubbles, have been extensively used to enhance the power of Doppler signals from blood. Myocardial contrast echocardiography is a relatively new method for studying myocardial perfusion. ${ }^{35}$ It has the potential to provide information on myocardial perfusion which perfectly complements the anatomical, functional, and haemodynamic information derived from routine echo studies.

This technique was first described with intra-aortic and intracoronary injections of contrast microbubbles to demonstrate myocardial perfusion. ${ }^{36}$ When the microbubbles enter the myocardium they cause an increase of backscattered ultrasound energy (power) and hence raise the myocardial grey level intensity in the image (fig 7).

Early contrast agents were derived by agitation of solutions such as indocyanine green, saline, dextrose, hydrogen peroxide, and blood to produce free gas bubbles of air. ${ }^{36}$ Unfortunately these bubbles that are not encapsulated have a wide range of diameters and the gas diffuses back into the liquid too quickly to allow widespread distribution in the body. Free gas bubbles cannot pass through the lungs so no opacification of the left heart can be achieved unless a right-to-left shunt is present.

Techniques have been devised to create encapsulated bubbles which have a longer life and can survive passage through the lungs. For example, a sonication technique produced microbubbles in human serum albumin (HSA) with diameters less than $10 \mu \mathrm{m} .{ }^{3738}$ Sonication is a technique which produces small microbubbles in a fluid by exposing it to very high intensity ultrasound, typically $20 \mathrm{kHz}$. Cavitation occurs causing small microbubbles to be produced in the fluid. The process of sonication is illustrated in figure 8 . There is at present considerable commercial research and development related to microbubble contrast agents. Some products which are undergoing trials are described below and in the table.

Albunex, marketed in Europe as Infoson (Nycomed, Norway) is made from sonication of $5 \% \mathrm{HSA}$ and has a shelf life of 6 months. Injections range from 0.025 to $1.0 \mathrm{ml} / \mathrm{kg}$. It is an isotonic, ready to use suspension of $5 \times 10^{8} / \mathrm{ml}$ air-filled microspheres with diameters of 4 to $10 \mu \mathrm{m} .{ }^{40}$ At room temperature the suspension remains stable for up to 20 weeks. ${ }^{41}$ Nycomed is currently developing a more stable agent called NUS, which will be marketed as a myocardial perfusion agent. This agent is also sonicated human serum albumin but the shell is degraded synthetic polymer.

Properties of some common left heart contrast agents

\begin{tabular}{|c|c|c|c|c|c|c|}
\hline Left heart agent & Manufacturer & Type of agent & Capsule & Gas & Bubble size & Dose/concentration * \\
\hline $\begin{array}{l}\text { Albunex } \\
\text { (Infoson in Europe) }\end{array}$ & $\begin{array}{l}\text { Nycomed } \\
\text { (Europe) } \\
\text { Mallinckrodt } \\
\text { (USA) }\end{array}$ & $\begin{array}{l}\text { Encapsulated } \\
\text { bubble }\end{array}$ & Albumin & Air & $\begin{array}{l}\text { Range }(4-10 \mu \mathrm{m}) \\
\text { mean } 4 \mu \mathrm{m}\end{array}$ & $0.025-1.0 \mathrm{ml} / \mathrm{kg}$ \\
\hline Levovist & Schering & $\begin{array}{l}\text { Encapsulated } \\
\text { bubble }\end{array}$ & Palmitic Acid & Air & $\begin{array}{l}\text { Range }(2-8 \mu \mathrm{m}), \\
\text { median } 3 \mu \mathrm{m}\end{array}$ & \multirow{2}{*}{$\begin{array}{l}17 \mathrm{ml} \text { of } 200 \mathrm{mg} / \mathrm{ml} \\
11 \mathrm{ml} \text { of } 300 \mathrm{mg} / \mathrm{ml} \\
8 \mathrm{ml} \text { of } 400 \mathrm{mg} / \mathrm{ml} \\
5 \mu 1 / \mathrm{kg}\end{array}$} \\
\hline Aerosomes & $\operatorname{ImaRx}$ & $\begin{array}{l}\text { Encapsulated } \\
\text { bubble }\end{array}$ & Lipid & $\mathrm{C}_{3} \mathrm{~F}_{8}$ & Mean $(2 \mu \mathrm{m})$ & \\
\hline Quantison & Andaris & $\begin{array}{l}\text { Encapsulated } \\
\text { bubble }\end{array}$ & HSA & Air & \multirow{2}{*}{$\begin{array}{l}\text { Mean }(3 \cdot 2 \mu \mathrm{m}) \text {, } \\
\text { range }(<2 \%>6 \mu \mathrm{m}) \\
\text { Range }(2-5 \mu \mathrm{m})\end{array}$} & $20-200 \mu \mathrm{l} / \mathrm{kg}$ \\
\hline Echogen & $\begin{array}{l}\text { Sonus } \\
\text { Pharmaceuticals }\end{array}$ & Phase-shift & N/A & Perfluoropentane & & $0.1 \mathrm{ml} / \mathrm{kg}$ \\
\hline
\end{tabular}

HSA = human serum albumin. 


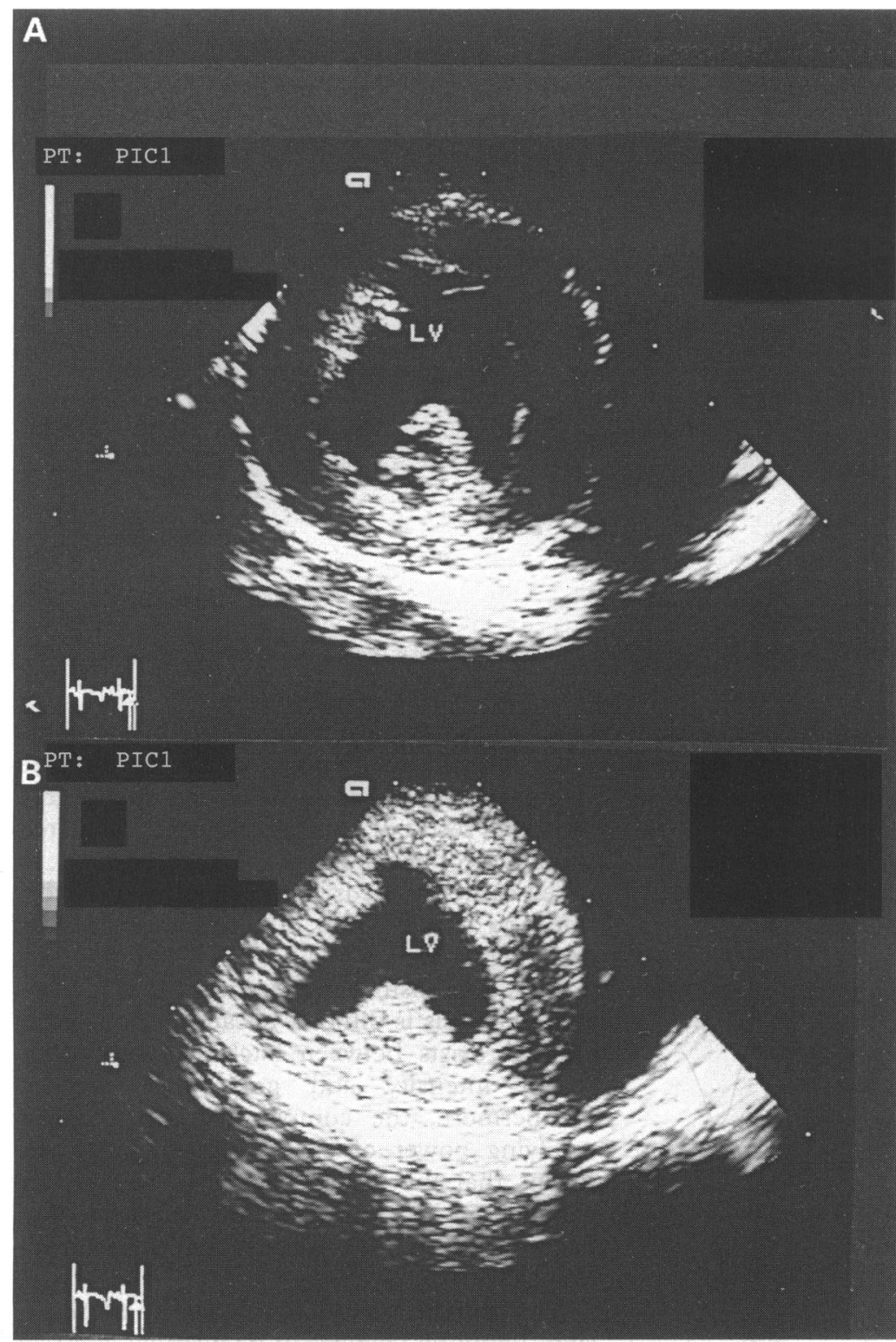

Figure 7 Enhancement of the echogenicity of the myocardium by a microbubble contrast agent. (A) Before and (B) after intra-aortic injection of Levovist in an open-chested pig study.

A saccharide-based agent, SHU 508A Levovist (Schering AG Laboratories, Berlin), has diameters ranging from 2 to $8 \mu \mathrm{m} .{ }^{42}$ The Levovist product comes in a vial containing granules and a low concentration of a physio-

Sonicator

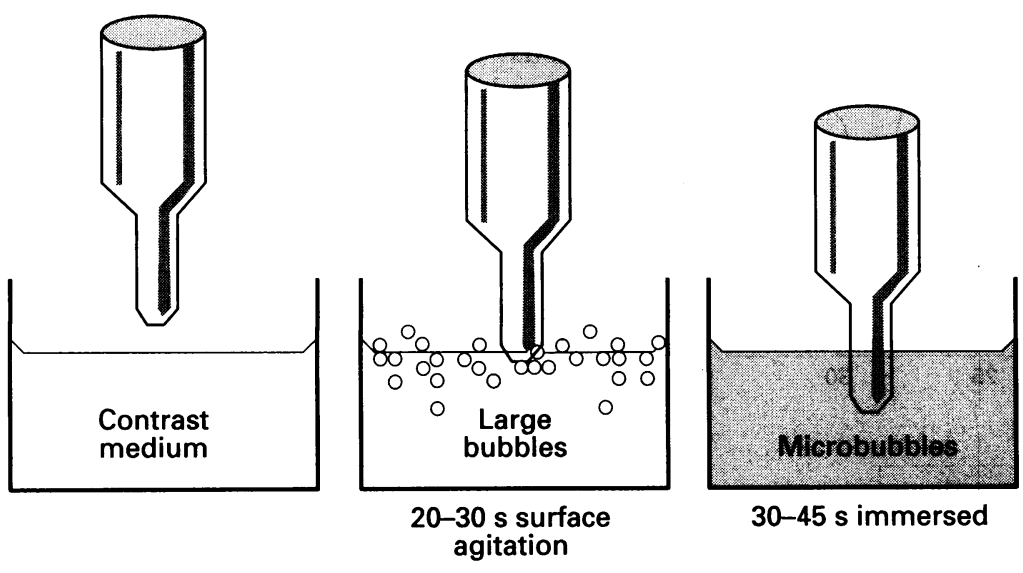

Figure 8 Sonication process with a low frequency ultrasonic horn source of $\mathrm{kHz}$ ultrasound. logical fatty acid. The granules are mixed vigorously with sterile water, creating a milky suspension of galactose microparticles. The rough surfaces of these galactose microparticles act as origin and adherence sites for bubbles stabilised by a monolayer shell of fatty acid. The microbubbles are of a limited size, about that of an erythrocyte. After injection of the suspension, the galactose microparticles dissolve within seconds to release the bubbles into the blood stream. Such bubbles can last for as long as $\mathbf{5}$ minutes, recirculating many times. Concentrations of between 200 and $400 \mathrm{mg} / \mathrm{ml}$ are used. Another example of a saccharide-based agent is SHU 454 Echovist (Schering AG Laboratories, Berlin). It has bubble diameters of 5 to $15 \mu \mathrm{m}$ and does not pass through the lungs to a significant extent. SHU 454 is used for right heart applications.

Aerosomes (ImaRx Pharmaceutical, Tucson, Arizona) are lipid-coated microbubbles containing fluorocarbon gas $\left(\mathrm{C}_{3} \mathrm{~F}_{8}\right) .{ }^{4344}$ There are on average 6 to $7 \times 10^{8} \mathrm{bubbles} / \mathrm{ml}$ with a mean diameter of $2 \mu \mathrm{m}$. The recommended dose is $5 \mu \mathrm{l} / \mathrm{kg}$. The agent is reported to be able to withstand pressures up to 300 $\mathrm{mmHg}$, an important consideration in myocardial imaging. The gas is exhaled from the body and does not seem to have toxic effects.

Quantison (Andaris, Nottingham) is another HSA gas encapsulated agent with microbubbles of a mean diameter of $3.2 \mu \mathrm{m}$ with less than $2 \%$ having diameters greater than $6 \mu \mathrm{m}$. The thickness of the shell of this agent can be varied between 100 and $200 \mathrm{~nm}$ to enable it to withstand high pressure. Andaris are also currently developing another agent, Quantison Depot and marketing this as a myocardial perfusion agent.

A third type of agent in addition to free and encapsulated bubbles is the phase-change agent which is injected into the body as a liquid and at body temperature converts into microbubbles. ${ }^{45} 46$ The agent (Echogen, QW3600) developed by Sonus Pharmaceuticals (Bothell, Washington, USA) is a perfluoropentane emulsion which vaporises to give bubbles with diameters of $2-5 \mu \mathrm{m}$. After intravenous injection, it clears from the blood stream in 30 to 40 minutes but attaches to the endocardium giving prolonged enhancement. The recommended dose for humans is 0.1 $\mathrm{ml} / \mathrm{kg}$. The above examples of contrast agents are quoted to illustrate the types known to be under development. There are at least 12 contrast agents in the preliminary stages of evaluation. An intravenous agent for myocardial perfusion has still to reach a stage of common acceptance.

TECHNOLOGY FOR CONTRAST STUDIES

Although much effort has been expended on the development of contrast agents, there has unfortunately been little progress on the development of ultrasound technology for the detection of myocardial contrast. Several dedicated computer systems for myocardial contrast echo have been described ${ }^{47-49}$ and used with intra-aortic injections. 


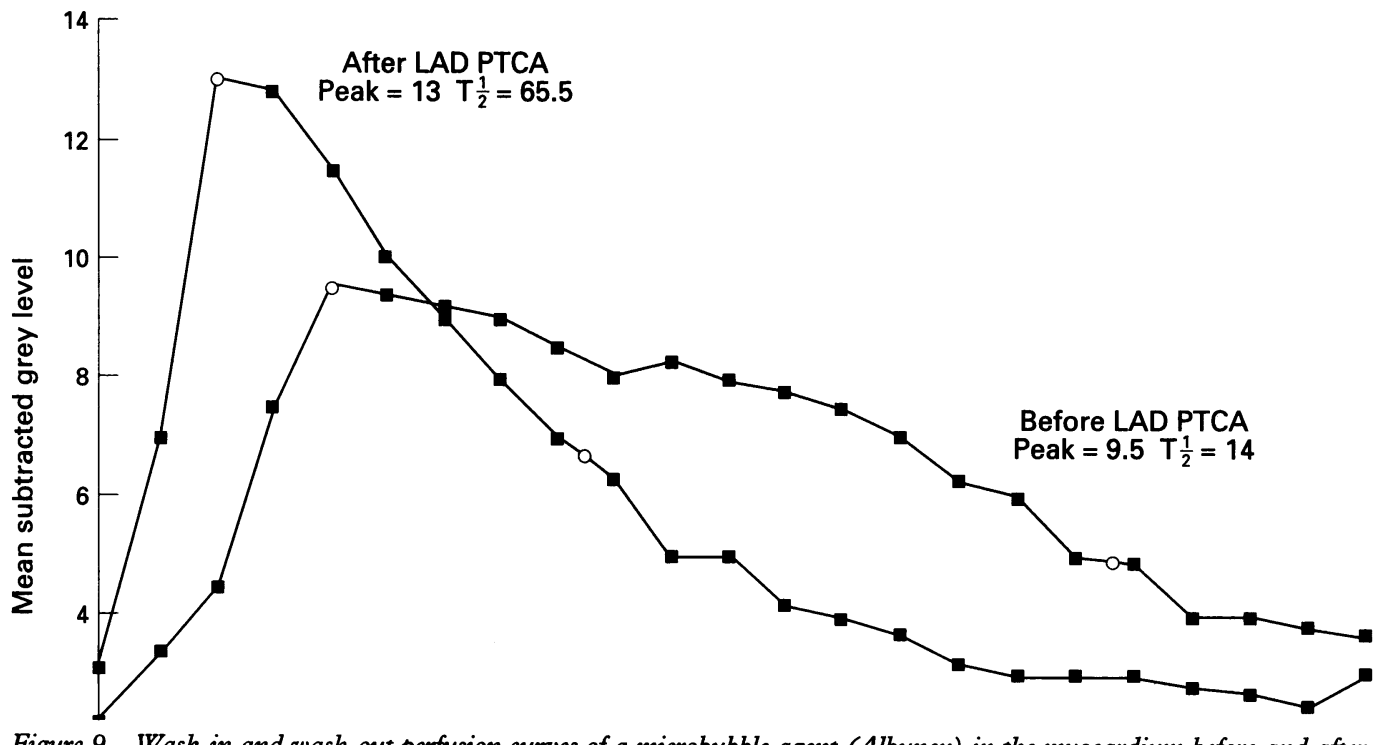
angioplasty (PTCA).

Most systems developed in individual centres have used small micro-computers and video frame grabbers. These acquire analogue video data from the video output on the ultrasound scanner. Once a series of echocardio-
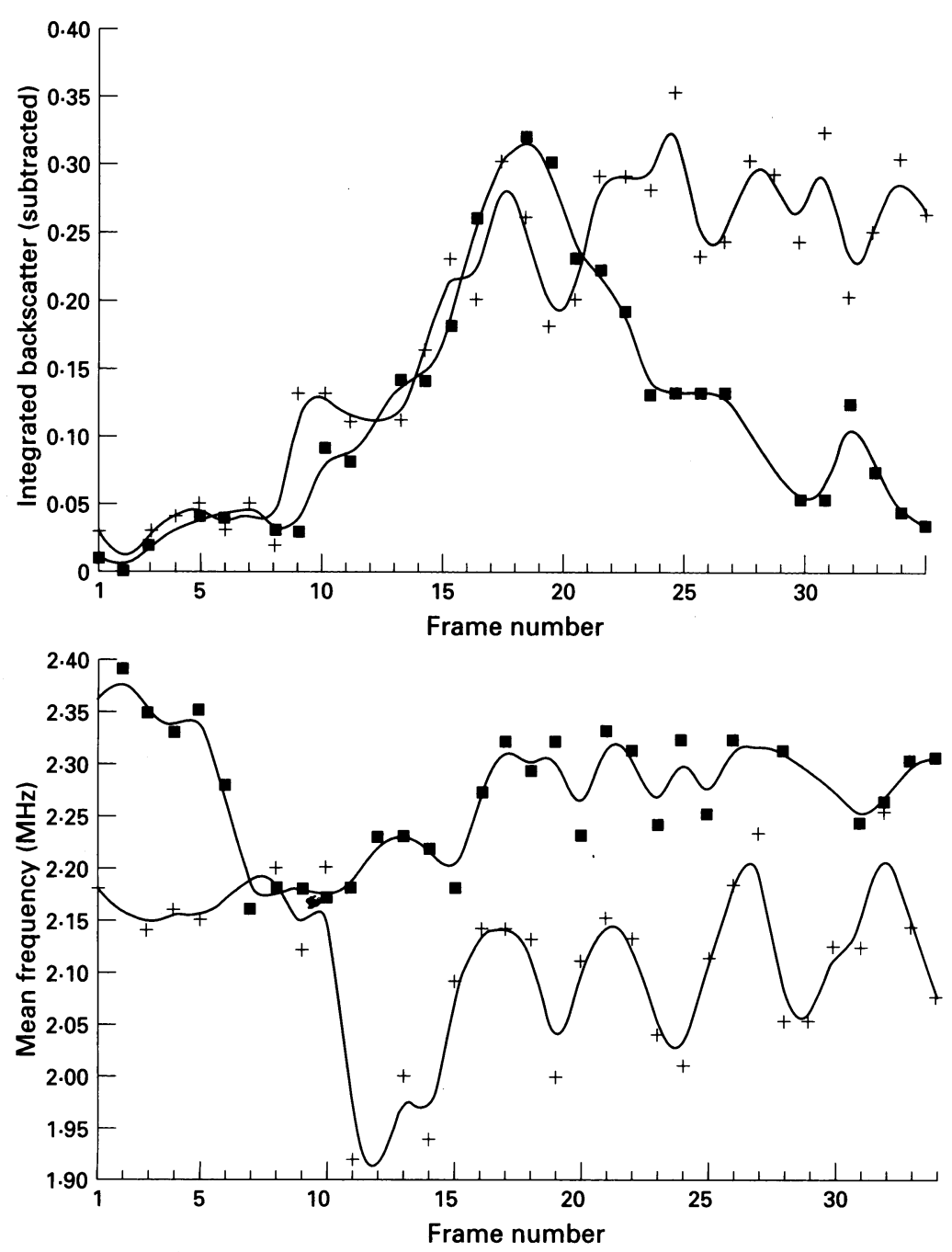

$\rightarrow-$ Left ventricle $\quad$ Myocardium

Figure 10 Variation of integrated backscatter and mean frequency of the ultrasound signals from the left ventricular chamber and myocardium after injection of a microbubble contrast agent (Albunex). Each frame corresponds to one cardiac cycle: frames are triggered from the $R$ wave of the electrocardiogram. graphic frames have been stored in the computer memory then an area of interest may be established on the image and changes in grey level as a result of contrast injection evaluated using video densitometry. Unfortunately, as noted earlier, there is a large amount of distortion and compression of ultrasound data by the imaging system.

This data distortion has meant that quantitative analysis is difficult because a non-linear relation exists between back-scattered ultrasound intensity and grey level display. Furthermore, the comparative low contrast resolving power of current imaging systems means that the small changes in backscatter echo intensity from the myocardium that occur as a result of intravenous contrast injection are not detectable.

To facilitate quantitative analysis of perfusion, temporal changes in myocardial contrast enhancement have been analysed. An area of interest may be positioned over any portion of the image and changes in the grey level values plotted against time. This provides a contrast wash-in and wash-out curve. These curves have been analysed in a number of different ways and parameters such as the peak grey level, wash-out half-time, area under curve and wash-in time have been utilised by several authors. ${ }^{50-54}$ An example of a perfusion curve is shown in figure 9.

Methods based upon backscatter signal intensity and grey level data seem adequate for intracoronary injections of contrast where changes in signal amplitude are relatively large. However, as previously mentioned, they appear insensitive for the detection of the very small quantities of microbubbles appearing in the myocardium after intravenous injection of transpulmonary agent. In addition, they have only been tested in experimental situations where image quality was optimum. ${ }^{55} 56$

Analysis of the unprocessed radiofrequency ultrasound signals, returning from the imaging transducer to the ultrasound system, may provide a sensitive method of detecting any small changes in backscattered signal amplitude. The radiofrequency signal may be analysed 
not only for changes in backscattered amplitude, but also for any changes in its frequency spectrum that might have occurred as a result of interaction with contrast microspheres. ${ }^{57}$ From an instrumentation point of view, it may be technically easier to create methods for analysis of small changes in frequency than small changes in amplitude. The backscatter from Albunex is frequency dependent and its resonant frequency appears to be within the bandwidth of cardiac diagnostic imaging transducers. Therefore, it is not surprising that significant changes in the mean frequency of the scattered signal may be seen after Albunex injections. ${ }^{58}$

Figure 10 illustrates the variation in myocardial integrated backscatter and the shift in mean frequency of the backscattered signal after Albunex was given to one patient. Frames correspond to cardiac cycles, frame acquisition being triggered from the $R$ wave of the ECG. An increase in myocardial integrated backscatter is seen, together with a fall in mean frequency of the backscattered signal. This latter phenomenon is thought to result from resonant absorption of certain parts of the transmitted ultrasound spectrum, ${ }^{58}$ which causes a net shift in the backscattered signal.

Pulse-echo grey shade and colour Doppler flow imaging techniques are being developed to extract information from the second harmonic of the backscattered signal from microbubbles. ${ }^{59}$ The second harmonic occurs at twice the frequency of the normal backscattered signal and is due to non-linear oscillation of the bubbles. A second harmonic component is not present in the backscattered signal from tissue and hence by examining it the microbubble signal is more clearly seen. Second harmonic imaging is expected to enhance the signal from bubbles in blood vessels by a factor in excess of $20 \mathrm{~dB}$.

Echocardiography has now been largely accepted as the gold standard for the evaluation of valvar heart disease, congenital heart disease, cardiomyopathies, pericardial disease, and left ventricular function. However, the technique has yet to make a significant impact upon the management of patients with ischaemic heart disease and most patients seen in any adult cardiology centre have ischaemic heart disease. The advent of myocardial contrast echocardiography should extend the role of echocardiography significantly into the assessment of ischaemic heart disease.

1 Bom N, ten Hoff H, Lancee CT, Gussenhoven WJ, Bosch JG. Early and recent intraluminal ultrasound devices. Int $\mathcal{F}$ Cardiac Imaging 1989;4:79-88.

2 Hoskins PR, McDicken WN. Techniques for the assessment of the imaging characteristics of intravascular ultrasound scanners. Br $¥$ Radiol $1994 \mathrm{~b} ; 67: 695-700$.

3 Dekker DL, Pizialli R, Dong EA. System of ultrasonically imaging the heart in three dimensions. Comput Biomed Res 1974;7:544-53.

4 Nikravesh PE, Skorton DJ, Chandran KB, Attarwala YM, Pandian N, Kerber RE. Computerised three-dimensional finite element reconstructions of the left ventricle from cross-sectional echocardiograms. Ultrasonic Imag 1984;6: 48-59.

5 Roelandt JRTC, Thomson IR, Vletter WB, Brommersma P, Bom N, Linker DT. Multiplane transesophageal echocardiography: latest evolution in an imaging revolution. $\mathcal{F} \mathrm{Am}$ Soc Echocardiogr 1992;5:361-7.
6 Roelandt JRTC, ten Cate FJ, Vletter WB, Taams MA. Ultrasonic dynamic three-dimensional visualisation of the heart with a multiplane transesophageal imaging transducer. $\mathcal{A} \mathrm{Am}$ Soc Echocardiogr 1994b;7:217-29.

7 Roelandt JRTC, di Mario C, Pandian NG, Wenguang L, Keane D, Slager CJ, et al. Three-dimensional reconstruction $\mathrm{f}$, Slager $\mathrm{CJ}$, et al. Three-dimensional reconstruction of intracorong rationale, 1994;90:1044-55.

8 Rosenfield K, Kaufman J, Pieczek AM, Langevin RE, Palefski PE, Razvi SA, et al. Human coronary and peripheral arteries: on-line three-dimensional reconstruction from two dimensional intravascular US scans. Radiology 1992;184:823-32.

9 Olshansky B, Collins SM, Skorton DJ, Prasad NV. Variation of left ventricular myocardial gray level on two-
dimensional echocardiograms as a result of cardiac condimensional echocardiograms as a r

10 Haendchem RV, Ong K, Fishbein MC, Zwehl W, Meerbaum S, Corday E. Early differentiation of infarcted and noninfarcted reperfused myocardium in dogs by quantitative analysis of regional myocardial echo amplitudes. Circ Res 1985;57:718-28

11 Skorton DJ, Melton HE, Pandian NG, Nichols J, Koyanagi $\mathrm{S}$, Marcus ML, et al. Detection of acute myocardial infarction in closed-chest dogs by analysis of regional two-dimensional echocardiographic gray-level distribution. Circ Res 1983;52:36-44.

12 O'Donnell M, Bauwens D, Mibs JW, Miller JG. Broadband integrated backscatter: an approach to spatially localized tissue characterisation in vivo. Proc IEEE Ultrason Symp 1979;79:175-8.

13 Lattanzi F, Picano E, Mazzarisi A, Landini L, Benassi A, Masini $M$, et al. In vivo radiofrequency ultrasound analysis of normal human heart structures. $\mathcal{F}$ Clin Ultrasound. 1987;15:371-5.

14 Picano E, Pelosi G, Marzilli M, Lattanzi F, Benassi A, Landini $L$, et al. In vivo quantitative ultrasonic evaluation of myocardial fibrosis in humans. Circulation 1990; 81:58-64.

15 Naito J, Masuyama T, Mano T, Yamamoto K, Doi Y, Kondo $\mathrm{H}$, et al. Validation of transthoracic myocardial ultrasonic tissue characterisation: comparison of transthoracic and open-chest measurements of integrated thoracic and open-chest measurements of inte

16 Wickline SA, Verdonk ED, Sobel BE, Miller JG. Identification of human myocardial infarction in vitro based on the frequency-dependence of ultrasonic backscatter. $\mathcal{F}$ Acoust Soc 1992;91:3018-25.

17 Rijsterborgh H, Mastik F, Lancee CT, Verdouw P, Roelandt J, Bom N. Ultrasound myocardial integrated backscatter signal processing: frequency domain versus time domain. Ultrasound Med Biol 1993;19:211-9.

18 Madaras EI, Barzilai B, Perez JE, Sobel BE, Miller JG. Changes in myocardial backscatter throughout the cardiac cycle. Ultrasonic Imag 1983;5:229-39.

19 Mimbs JW, Bauwens D, Cohen RD, O'Donnell M, Miller JG, Sobel BE. Effects of myocardial ischemia on quantitative ultrasonic backscatter and identification of responsible determinants. Circ Res 1981:49;89-96.

20 O'Donnell M, Mimbs JW, Miller JG. Relationship between collagen and ultrasonic backscatter in myocardial tissue. f Acoust Soc Am 1981;69:580-8.

21 Cohen RD, Mottley JG, Miller JG, Kurnik PB, Sobel BE. Detection of ischemic myocardium in vivo through the chest wall by quantitative ultrasonic tissue characterisation. Am $\mathcal{F}$ Cardiol 1982;50:838-43.

22 Sagar KB, Pele LR, Rhyne TL, Howard J, Warltier DC. Estimation of myocardial infarct size with ultrasonic tissue characterization. Circulation 1991;83:1419-28.

23 Barzilai B, Madaras EI, Sobel BE, Miller JG, Perez JE. Effects of myocardial contraction on ultrasonic backscatter before and after ischemia. Am Physiol Soc 1984;247: ter before

24 Wickline SA, Thomas LJ, Miller JG, Sobel BE, Perez JE. Sensitive detection of the effects of reperfusion on myocardium by ultrasonic tissue characterization with integrated backscatter. Circulation 1986;74:389-400.

25 Glueck RM, Mottley JG, Miller JG, Sobel BE, Perez JE. Effects of coronary artery occlusion and reperfusion on cardiac cycle-dependent variation of myocardial ultrasonic backscatter. Circ Res 1985;56:683-9.

26 Barzilai B, Vered Z, Mohr GA, Wear KA, Courtois M, Sobel BE, et al. Myocardial ultrasonic backscatter for characterization of ischemia and reperfusion: relationship to wall motion. Ultrasound Med Biol 1990;16:391-8.

27 Sagar KB, Pele LR, Rhyne TL, Komorowski RA, Wann LS, Warltier DC. Role of ultrasonic tissue characterisation to distinguish reversible from irreversible myocardial injury. F Am Soc Echocardiogr 1990;3:471-7.

28 Mimbs JW, O'Donnell M, Miller JG, Sobel BE. Detection of cardiomyopathic changes induced by Doxorubicin based on quantitative analysis of ultrasonic backscatter. Am $\mathcal{F}$ Cardiol 1981;47:1056-60.

29 Perez JE, Barzilai B, Madaras EI, Glueck RM, Saffitz JE, Johnston P, et al. Applicability of ultrasonic tissue characterization for longitudinal assessment and differentiation of calcification and fibrosis in cardiomyopathy. $₹ \mathrm{Am} \mathrm{Coll}$ Cardiol 1984;4:88-95.

30 Lattanzi F, Spirito P, Picano E, Mazzarisi A, Landini L, Distante A, et al. Quantitative assessment of ultrasonic myocardial reflectivity in hypertrophic cardiomyopathy. $\mathcal{F}$

31 Naito J, Masuyama T, Tanouchi J, Mano T, Kondo H, 
Yamamoto $\mathrm{K}$, et al. Analysis of transmural trend of myocardial integrated ultrasound backscatter for differentiation of hypertrophic cardiomyopathy and ventricula hypertrophy due to hypertension. $₹ \mathrm{Am}$ Coll Cardiol 1994;24:517-24

32 Vered Z, Barzilia B, Mohr BA, Thomas LJ, Genton R, Sobel BE, et al. Quantitative ultrasonic tissue characterisation with real-time integrated backscatter imaging in ation with real-cume integrated backscatter imaging in diomyopathy. Circulation 1987;5:1067-73.

33 Vandenberg BF, Rath I, Shoup TA, Kerber RE, Collins SM, Skorton DJ. Cyclic variation of ultrasound backsat studies with real time backscatter imaging system. $\mathcal{F} \mathrm{Am}$ Soc Echocardiogr 1989;2:308-14.

34 Lange A, Moran CM, Palka P, Fenn LN, Sutherland GR McDicken WN. The variation of integrated backscatter in human hearts from different ultrasonic transthoracic in human hearts from different ultrasonic

35 Kaul S, Force T. Assessment of myocardial perfusion with contrast two-dimensional echocardiography. In: Weyman AE, ed. Principles and practice of echocardiography. 2 nd ed. Lea and Febiger 1993;687

36 Bommer WJ, Miller L, Takeda P, Mason DT, De Maria ANL. Contrast echocardiography: Pulmonary transmission and myocardial perfusion injury using surfactant stabilized microbubbles. Circulation 1979;59:IV-203.

37 Ziskin MC, Bonakdapour A, Weinstein DP, Lynch PR Contrast agents for diagnostic ultrasound. Invest Radio 1972;7:500-5.

38 Feinstein SB, ten Cate FJ, Zwehl W, Ong K, Maure G, Tei C, et al. Two dimensional contrast echocardiography, 1: in vivo development and quantitative analysis of echo contrast agents. $f$ Am Coll Cardiol 1984 3:14-20.

39 Keller MW, Segal SS, Kaul S, Duling BR. The behaviour of sonicated albumin microbubbles in the microcircula tion: A basis for their use as myocardial echo contrast agents. $\mathcal{F}$ Am Coll Cardiol 1988;11:75A.

40 Feinstein SB, Heindrich PA, Dick CD, Schneider JM, Pastoret AF, Rubenstein WA, et al. Albunex: A new intravascular ultrasound contrast agent: Preliminary safety and efficacy results. Circulation 1988;78:II-565.

41 Barnhart J, Leven H, Villapando E. Characteristics of Albunex: Air-filled albumin microspheres for echocardiography contrast enhancement. Invest Radiol 1990;25: graphy

42 Fritsch T, Hilmann J, Kampfe M. SHU 508A a transpulmonary echo contrast agent: Initial experience. Invest

43 Unger E, Lund PJ, Shen DK, Fritz TA, Yellowhair DE, New TE. Nitrogen-filled liposomes as a vascular US contrast agent: Preliminary evaluation. Radiology 1992 185:453-6.

44 Unger E, Shen DK, Fritz T, Lund P, Wu GL, Kulik B, et al Gas-filled liposomes as echocardiographic contras agents in rabbits with myocardial infarcts. Invest Radiol 1993;28:1155-9.
45 Quay SC. Ultrasound contrast agent development: Phase shift colloids (abstract). F Ultrasound Med 1994;13:S9.

46 Beppu S, Matsuda H, Shishido T, Miyatake K. Success of myocardiol contrast echocardiography by peripheral venous injection methods: Visualisation of area at risk. Circulation 1993;88:I-401.

47 Ong K, Maurer G, Feinstein S, Zwehl W, Meerbaum S, Conday E. Computer methods for myocardial contrast 1984;3:1212-8.

48 Maurer G, Ong $K$, Haendchen $R$, Torres $M$, Tei C, Wood F, et al. Myocardial contrast two-dimensional echocardiography: comparison of contrast disappearance rates in normal and underperfused myocardium. Circulation 1984;69:418-29.

49 Powsner SM, Wood J, Prieto P, Charleston D, Feinstein SB. Computer acquisition of echocardiographic data for
contrast studies of myocardial perfusion. Circulation contrast studies of $1987 ; 76$ :suppl IV:505.

50 Powsner SM, Keller MW, Saniie J, Feinstein SB. Quantitation of echo contrast effects. Am $\mathcal{F}$ Physiol Imag 1987;1:124-8.

51 Monaghan MJ, Quigley PJ, Metcalfe JM, Jewitt DE. Assessment of myocardial perfusion by contrast enhanced digital subtraction echocardiography. $\mathcal{F} A m$ Coll Cardiol 1987;9:112A

52 Monaghan MJ, Quigley PJ, Metcalfe JM, Thomas SD Jewitt DE. Digital subtraction contrast echocardiography: A new method for the evaluation of regional myocardial perfusion. Br Heart f 1988;59:12-9.

53 ten Cate FJ, Serruys PW, Huang H, de Jong N, Roelandt J. Is the rate of disappearance of echo contrast from the interventricular septum a measure of left anterior descending stenosis? Eur Heart $₹$ 1988;9:728-833.

54 Dick CD, Heidenreich P, Aronson S, Gluck D, Tamler B, Feinstein SB. Reproducible myocardial perfusion with intravenous contrast echocardiography. Circulation 1988 ; 78 suppl II:5664.

55 Skyba DM, Jawaweera AR, Goodman NC, Ismail S, Camarano GP, Kaul S. Quantification of myocardial perfusion with myocardial contrast echocardiography from left arterial injection of contrast: implications for venous injection. Circulation 1994;90:1513-21.

56 de Jong N, Hoff L Skotland T, Bom N. Absorption and scatter of encapsulated gas filled microspheres: theoretical considerations and some measurements. Ultrasonics 1992;2:95-103.

57 Glass JM, Yao LX, Rahko PS, Zagzebski JA. Frequency dependence of the backscatter coefficient of Albunex dependence of the backscatter coefficie
(abstract). $\mathcal{A} \mathrm{Am}$ Coll Cardiol 1991;17:349.

58 Monaghan MJ, Metcalfe JM, Odunlami S, Thomas SD, Waaler A, Jewitt DE. Digital radiofrequency echocardiog raphy in the detection of myocardial contrast followin intravenous administration of Albunex. Eur Heart $\mathcal{F} 1993$ 14:1200-19.

59 Burns PN, Powers JE, Fritzsch T. Harmonic imaging: new imaging and Doppler method for contrast-enhanced ultrasound. Radiology 1992;182(P):142. 